have been combined with a similar electronic corpus being collected by the reading programme in Oxford.

The NARP quotations have been taken from a wide variety of general, regional, and special subject texts of North American provenance. A recent count showed that over 5,500 individual texts have been perused by readers looking for examples of new words or new senses of words, ethnic or regional expressions, and special subject vocabulary (e.g. terms from baseball, computing, cooking and food, law-enforcement, Native American studies, plumbing, etc.).
More recently, as the $O E D$ revision process has moved into full swing, the NARP has been actively engaged in reading historical sources as well. These include diaries, collections of letters and personal papers, historical non-fiction sources, and works by previously neglected authors (such as the Schornberg Library of Nineteenth-Century Black Women Writers). The purpose is to build regional, diachronic depth into the electronic quotation database that will be used to ensure that the new $O E D$ remains the English dictionary of record in the twenty-first century and beyond.

\title{
Editions and Adaptations of Shakespeare
}

\section{(press release)}

Chadwyck-Healey announces the publication of an important new resource on CD-ROM for Shakespeare scholars, Editions and Adaptations of Shakespeare, which contains eleven major editions of Shakespeare's work, twenty-four separate contemporary printings of individual plays, selected apocrypha and related works and more than one hundred adaptations, sequels and burlesques from the seventeenth, eighteenth and nineteenth centuries.

Editions and Adaptations of Shakespeare brings together for the first time in a single electronic database the First Folio of 1623 and the most important of the original quarto and octavo printings of individual plays, which between them are the focus of so much of the textual debate surrounding Shakespeare. The collection culminates in the Cambridge edition of 1863-6, which is the basis for the famous and popular Globe edition and which still profoundly influences the majority of the twentieth-century editions of Shakespeare.

Every text within the database is reproduced in full, including all prefatory matter and annotations. Facsimile reproductions of the title pages and any illustrations from the original editions are included along with a selection of pages of text.

Editions and Adaptations of Shakespeare is the only electronic version of Shakespeare's works that enables different editions and adaptations to be compared. A powerful feature of the software enables users to display different versions of a text on screen at the same time for the purpose of comparison. Links between the parallel texts enable users to move easily between them, opening up these texts to investigation by Shakespeare scholars and students, literary theorists and cultural historians in ways never before possible.

A wide selection of theatre adaptations of Shakespeare's plays is included. The core is Bell's Acting Edition (1774) which contains versions of thirty-six of Shakespeare's plays. This is supplemented by over seventy-five adaptations of individual plays from the seventeenth, eighteenth and nineteenth centuries, including works by John Dryden, Nahum Tate, Colley Cibber and John Kemble.

The software for the CD-ROM edition is based on that used for Chadwyck-Healey's earlier full-text literary databases, English Poetry and English Verse Drama. Users are able to carry out sophisticated searches on any word or phrase in the text or title of any edition or adaptation in the entire database; restrict searches to editions or adaptations only, to a specific genre, play, act, scene or speaker or limit a search to the works of an author of adaptations, to songs and lyrics and to stage instructions. Authorial and editorial notes and prefatory and end matter can be included in or excluded from a search or can be searched exclusively.

Editions and Adaptations of Shakespeare costs $£ 2,500$.

For further information please contact: Emma Rintoul, Chadwyck-Healey Ltd, The Quorum, Barnwell Road, Cambridge CB5 8SW. Tel: 01223 215512. Fax: 01223 215514. Email: rintoul@chadwyck.co.uk 